\title{
Electrodeposition of Polypyrrole/Carboxymethyl Cellulose on Platinum and Indium Tin Oxide
}

\author{
Carlucio Roberto Alves, Pilar Herrasti, ${ }^{*}{ }^{\dagger}$ Pilar Ocón, ${ }^{*}$ Luis Alberto AvaCA, and Toribio Fernandez Otero ${ }^{* *}$ \\ Universidade de Sâo Paulo, Instituto de Química de Sâo Carlos, Grupo de Materiais \\ Electródicos e Métodos Electro analíticos, 13560-970 Sâo Carlos, Brazil \\ * Universidad Autónoma de Madrid, Departamento de Química Física Aplicada, 28049 Madrid, Spain \\ ** Universidad del País Vasco, Facultad de Química, Departamento de Química Física, \\ Laboratorio de Electroquímica, 20080 San Sebastián, Spain
}

(Received October 2, 2000; Accepted December 12, 2000)

\begin{abstract}
The paper presents information on the synthesis and properties of a composite material consisting of an electronically conducting polymer and a polyanion. This kind of materials are of current interest. Polypyrrole- carboxymethyl cellulose composite have been studied on two different substrates: platinum and indium tin oxide. Electrochemical, SEM, and U.V-visible techniques have been used. The mechanism in both electrodes seem to be the same, but the morphology was quite different with the same electrodeposition conditions. Dendritycal growth on indium tin oxide in special conditions has been observed.
\end{abstract}

KEY WORDS Polypyrrole / Electropolymerization / Carboxymethylcellulose / Polymer Morphology / Conductivity /

In the last few years conducting polymers, particularly in the form of thin films on electrodes surfaces have received considerable attention. A number of publications have demonstrated the possibilities of using these polymer films. Some examples are: as electrochemical sensors, ${ }^{1-3}$ electronic devices, ${ }^{4,5}$ rechargeable batteries, ${ }^{6}$ photoelectrochemical cells ${ }^{7}$ and controlled drug release. $^{8,9}$

Several studies have reported on the early stages of deposition of polypyrrole films onto metal, indium oxide or vitreous carbon electrodes. ${ }^{10-12}$ In all cases, the cyclic voltammograms show nucleation loops, such a behavior is good evidence that the formation of a conducting polymer layer occurs by a mechanism involving nucleation of centres of the new phase followed by a three dimensional growth.

This kind of mechanism has been proposed when polypyrrole was electrodeposited from a solution containing small anions such as $\mathrm{ClO}_{4}^{-13}$ This and other polymers can be obtained when multy-charged anions called polyanions are used. The interaction between the positively charged polyheterocycle and the charge compensating polyanion forces intimate mixing of the two polymers. The mechanism in the last case has been less studied.

On the other hand, the degree of molecular ordering of a conductive polymer is determined by a combination of different factors. Among these are: The steric/ electronic nature of the monomer unit and the method and conditions of polymer preparation. Another very important factor is the nature of the incorporated dopant anion. For example, significant morphological differences should exist in a given or polyanion as opposed to a small inorganic dopant.

The most important purpose of this work is to assess the role of carboximethyl cellulose in morphology. Different papers in the thermoplastic field have been pub- lished with wood cellulose, these first works showed problems with the hidrophilic incompatibilities of absorption of water in the cellulose fiber and hydrophobic of the thermoplastic matrix. These results gave composites with poor technological properties. In the last few years new perspectives in this field have emerged using biodegradable composites. In this way the chemical and electrochemical production of composites such as polypyrrole/carboximethyl cellulose could yield a chemically modified biodegradable biopolymer with polyelectrolyte properties. The morphology of the blend obtained had been studied by electron scanning microscopy. As well as an investigation of the characteristic of the polypyrrole grown in solutions containing polyanion (carboxymethyl-cellulose CMC) is presented. The early stages of deposition were investigated by cyclic voltammetry and their response to potential steps.

\section{EXPERIMENTAL}

Electrochemical experiments were performed using an EG\&G PAR potentiostat/galvanostat Model 273, connected to a PS-55 IBM computer.

The experiments were carried out in a one compartment, three electrode cell. The reference electrode, was SCE, the counter electrode $\mathrm{Pt}$ and the working electrode was plate $1.0 \mathrm{~cm}^{2}$ or disk $0.071 \mathrm{~cm}^{2}$ or microelectrode 1.8 $\times 10^{-5} \mathrm{~cm}^{2}$ Platinum, they were polished with $1,0.3$, and then $0.05 \mu \mathrm{m}$ alumina powder on a polishing cloth before each experiment. Indium tin oxide was also used in same experiments like working electrode.

Solutions were prepared using triply distilled water. Pyrrole (Aldrich chemicals) was distilled under vacuum and stored in $\mathrm{N}_{2}$ in a refrigerator. Carboxymethyl cellulose

\footnotetext{
${ }^{\dagger}$ To whom correspondence should be addressed (E-mail: pilar.herrasti@uam.es).
} 


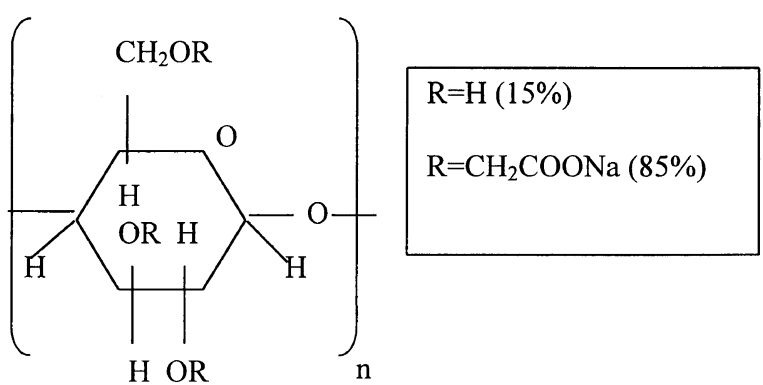

with an average molecular weight of $366 \mathrm{~g} \mathrm{~mol}^{-1}$, and being the $\mathrm{COO}^{-}$units a $30.6 \%(\mathrm{w} / \mathrm{w})$, (Fluka 99.5\%) was used as received. The $\mathrm{pH}$ of solution was approximately 6.

Electrolysis at different potentials were carried out. Products formed during anodic oxidation and that accumulated in the solution were analysed by UV visible spectroscopy using Shimadzu Spectrophotometer.

SEM micrographs were performed with a Phillips scanning electron microscopy.

\section{RESULTS AND DISCUSSION}

\section{Electrodeposition of Polypyrrole-Carboximethyl Cellulose Composite on Platinum}

Figure 1 shows a typical cyclic voltammogram obtained (curve b) by electropolymerization of pyrrole (Py) $\left(-1000\right.$ to $1600 \mathrm{mV} v s$. SCE, $\left.20 \mathrm{mV} \mathrm{s}^{-1}\right)$, in the presence of sodium carboximethyl cellulose ( $\mathrm{NaCMC}$ ), compared with cyclic voltammogram in NaCMC (curve a). The water discharge occurred at $1100 \mathrm{mV}$ in carboximethyl cellulose. When the monomer was present, the water discharge shifted towards higher anodic potentials and a prepeak appeared at $750 \mathrm{~m} \mathrm{~V}$ (process I) followed by a maximum at $1140 \mathrm{mV}$ (process II). A charge of $350 \mu \mathrm{C}$ $\mathrm{cm}^{-2}$, corresponding approximately to a monolayer, was involved in process I. On consecutive voltammograms only the initial sweep showed this shoulder indicating their irreversibility. During process II a black film of polymer was formed on the electrode. Current densities in process II and electropolymerization rates increased at higher concentrations of $\left(\mathrm{CMC}^{-}\right)$. When the concentration of pyrrole increased, the current density of the peak did not follow a linear variation. This fact indicates that the polymerization mechanism changes at different concentrations. In order to avoid those changes we used a $0.1 \mathrm{M}$ Py concentration, or small variations around this value.

Figure 2 shows cyclic voltammograms obtained using a clean platinum microelectrode in an aqueous solution containing only CMC (curve a) and (curve b) with pyrrole. In curve a two different oxidative processes can be observed. One at $-290 \mathrm{mV}$ (I) with a reduction peak (I)' and the other one at $1500 \mathrm{mV}$ (II) with the reverse at $1510 \mathrm{mV}$ (II)' when polypyrrole was added the first peak called b corresponds to the oxidation of CMC and two more peaks appeared the first one due to the adsorption of CMC, and the second one due to the oxidation of pyrrole, in the forward scan no reduction peaks were observed, indicating the irreversibility of the process.

In both cases (macro and micro) after the first cycle a polymer film was observed on the electrode.

The relationships between peak current (ip) and

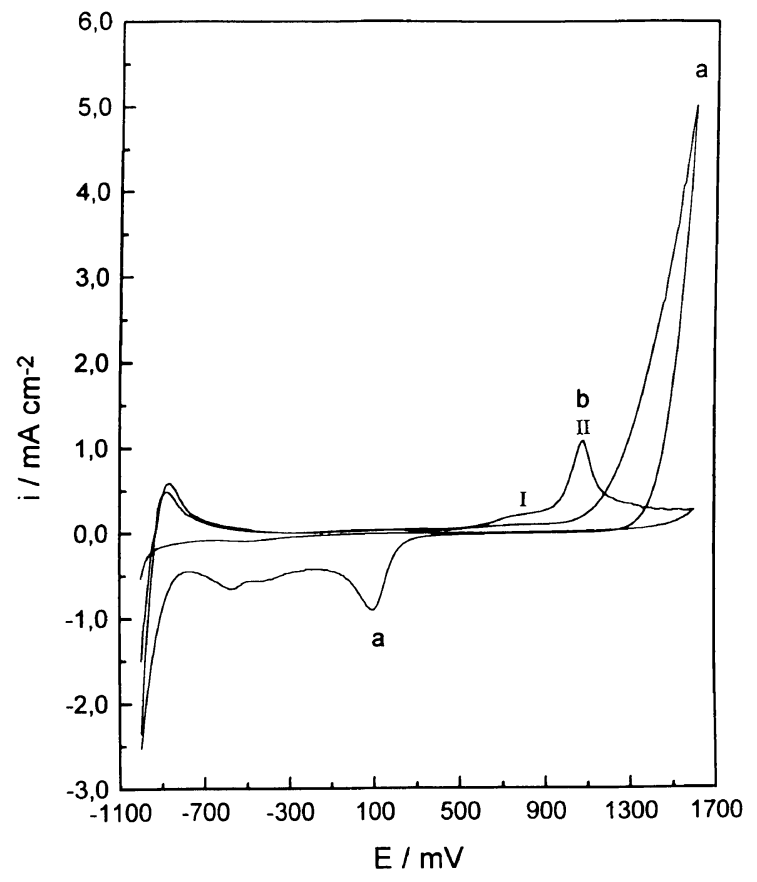

Figure 1. Cyclic voltammograms obtained on $\mathrm{Pt}$ macroelectrode in aqueous solutions containing $[\mathrm{NaCMC}]=0.1 \mathrm{M}$ (curve a) and $[\mathrm{NaCMC}]=[\mathrm{Py}]=0.1 \mathrm{M}$ (curve b) sweep rate $20 \mathrm{mV} \mathrm{s}^{-1}$.

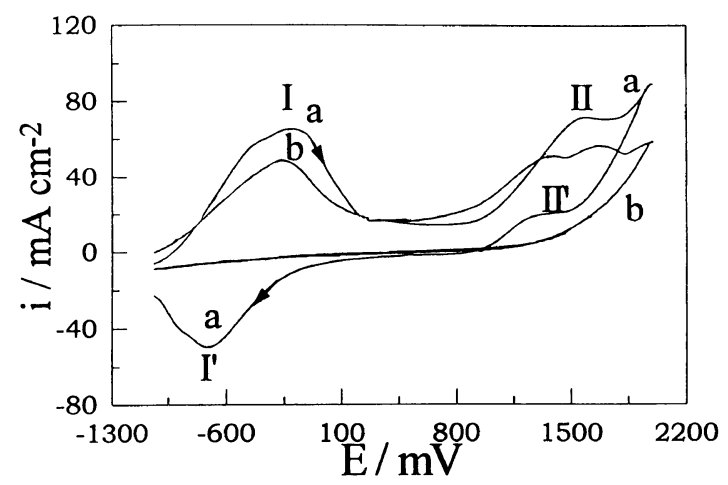

Figure 2. Cyclic voltammograms obtained on $\mathrm{Pt}$ microelectrode in aqueous solutions containing $[\mathrm{NaCMC}]=[\mathrm{Py}]=0.1 \mathrm{M}$ sweep rate $30 \mathrm{~V} \mathrm{~s}^{-1}$

sweep rate $(\mathrm{v})$ related to both maxima showed different evolutions (Figure 3). It is known that in surface processes ip is proportional to $\mathrm{v}$, changing as $\mathrm{v}^{1 / 2}$ in processes occurring under diffusion control. This figure shows the first peak (process I) in macroelectrode was proportional to $\mathrm{v}$ (Figure $3 \mathrm{a}$ ) and the second one (process II) proportional to $\mathrm{v}^{1 / 2}$ (Figure $3 \mathrm{~b}$ ). This fact points to a surface control of the initial process and a diffusion control of the second one.

Figure 4 shows cyclic voltammograms in NaCMC and pyrrole solution, using a platinum rotating disc electrode, at different rotation rates. The most significant feature of these traces is that the current decreased as the rotation rate increased. A similar result was found by Scharifker et $a l .{ }^{13}$ studying electrodeposition using small anions. The presence of polypyrrole-CMC on the electrode surface was verified after each of these experiments; the amount of the composite on the substrate decreased as the rotation rate increased. Increasing rota- 

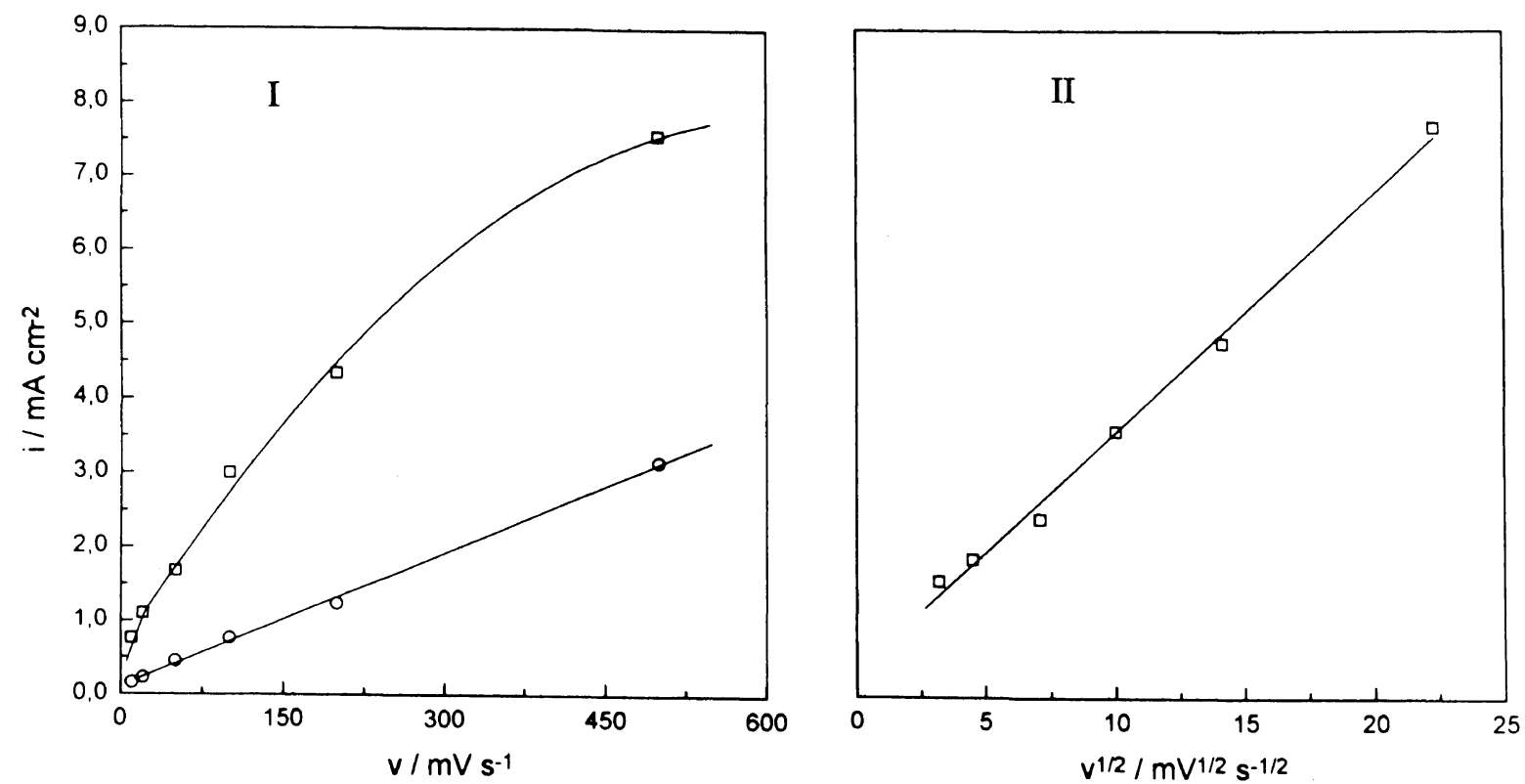

Figure 3. Peak current $v s . v$ and $\mathrm{v}^{1 / 2}$ for the process I and II of the Figure 1. Sweep rates: 10, 20, 50, 100, 200, and $500 \mathrm{mV} \mathrm{s}^{-1}$.

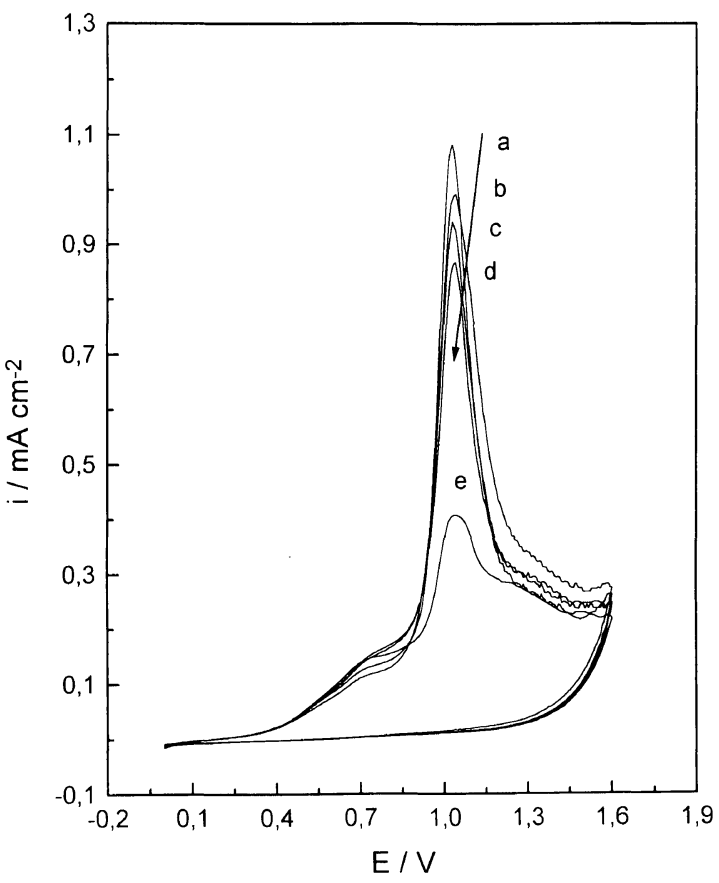

Figure 4. Cyclic voltammograms obtained on $\mathrm{Pt}$ in solutions containing $[\mathrm{NaCMC}]=[\mathrm{Py}]=0.1 \mathrm{M}$ for different rotating rates: a) 500 , b) 1000 , c) 1500, d) 2000 , and e) $3000 \mathrm{rpm}$. Sweep rate $20 \mathrm{mV} \mathrm{s}^{-1}$.

tion rates removed oligomers from the electrode neighbourhoods and this reduces the amount of deposited polypyrrole. The overall rate of the reaction was thus reduced as intermediate products were transported away from the electrode in stirred solutions. When the rotation of the electrode was very high the polymerization process stopped. Similar results were observed under potentiostatic experiments.

Two mechanisms were postulated in the literature to explain the electrodeposition of polypyrrole from solutions containing small anions. The oligomerization process occurred through the coupling, in the solution, of radical cations produced by the oxidation of the monomer on the electrode surface, resulting in dications and the release of two protons, in this scheme some reactions occurred in solution. ${ }^{14,15}$ The second scheme considered oligomerization resulting by a coupling between a radical cation and a monomeric molecule on the electrode surface. In this case only heterogeneous reactions at the electrode-solution interface were considered. ${ }^{16}$

In our case we have detected the formation of soluble products during anodic oxidation of pyrrole. In order to detect these soluble products we used UV-visible spectroscopy. During electrolysis different fractions of the solution were separated and analysed.

Figure 5 shows spectra from solutions obtained after different periods of electrolysis. A strong absorption band was observed at $248 \mathrm{~nm}$. After short periods of electrolysis, a new absorption bands appeared at 303 and $336 \mathrm{~nm}$. These values showed a shift of $40 \mathrm{~nm}$ related to the absorption bands described in other studies from pyrrole, bipyrrole and terpyrrole. ${ }^{17}$ The observed shift can be due to the interactions between the oligomers and the CMC present in solution. A change in the solution $\mathrm{pH}$ corresponding to $\mathrm{pH}=2$ produced a change in the absorption spectrum. At long polarization times a new peak appeared at a high wavelength (462 $\mathrm{nm})$, corresponding to a longer polymer chain. The wavelength of maxima increased at increasing chain length. ${ }^{18}$ UV measurements were taken during the polypyrrole electrodeposition from solutions containing small anions, this demonstrated the formation of pyrrole oligomers containing up to nine monomer units. ${ }^{19,20}$ At the same time the $\mathrm{pH}$ of the solution dropped down to 2 . Similar species also can be formed in solutions containing polyelectrolytes (in this case $\mathrm{CMC}^{-}$).

Results from cyclic voltammetry and UV, allowed us to propose a mechanism for the electrogeneration of Ppy/ $\mathrm{CMC}^{-}$composite films on platinum. The pre-peak observed by cyclic voltammetry was due to the oxidationabsorption of CMC on the Pt electrode (Process I). The 


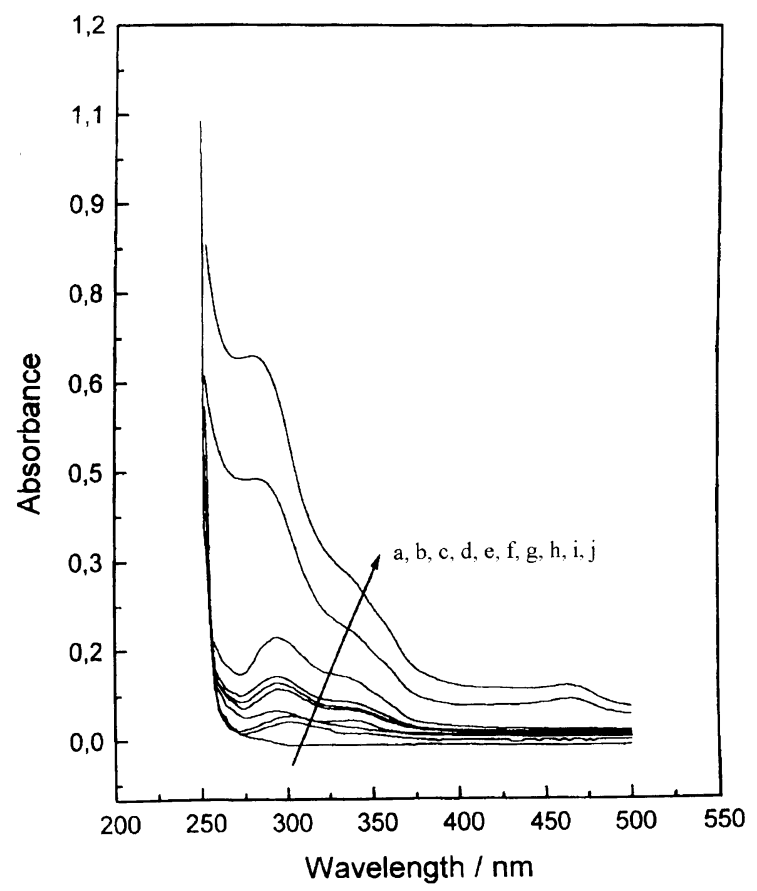

Figure 5. U.V - visible spectra of the electrolysis during the deposition of the Ppy/CMC composite in solution containing, Py 0.1 $\mathrm{M}$ and NaCMC 0.1 M. The background was a solution of NaCMC electrolysis times: a) 0 , b) 0.5 , c) 2 , d) 1.5 , e) 2 , f) 4 , g) 8 , h) 10 , i) 20 , and j) $30 \mathrm{~h}$.

CMC helped the incorporation of the radical cation to the surface of the electrode following the reactions

$$
\begin{array}{ll}
\text { I } & \mathrm{Pt}+\mathrm{CMC}^{-} \rightarrow \mathrm{Pt} / \mathrm{CMC}_{(\mathrm{ads})}+\mathrm{e}^{-} \\
\text {II } & \mathrm{Py}_{(\mathrm{sol})} \rightarrow \mathrm{Py}^{+}{ }_{(\mathrm{sol})}+\mathrm{e}^{-} \\
& \mathrm{Py}^{+}{ }_{(\mathrm{sol})}+\mathrm{Pt} / \mathrm{CMC}_{(\mathrm{ads})}^{-} \rightarrow \mathrm{Pt} /\left[\mathrm{CMC}^{-} \mathrm{Py}^{+}\right]_{\text {ads }}
\end{array}
$$

Reactions I and II are under surface and diffusion control, respectively. After this initiation, the propagation process takes place through the formation of oligomers in the solution, this was supported by ultraviolet measurements, following the reactions:

$$
\begin{array}{ll}
\text { III } & 2 \mathrm{Py}^{+}{ }_{(\text {sol })} \rightarrow \mathrm{Py}_{2}^{2+} \\
\text { IV } & \mathrm{Py}_{2}^{2+} \rightarrow \mathrm{Py}_{2}+2 \mathrm{H}^{+} \\
\text {V } & \mathrm{Py}_{n}^{+}+\mathrm{Py} \rightarrow \mathrm{Py}_{n+1}+\mathrm{e}^{-}+2 \mathrm{H}^{+}
\end{array}
$$

According to this polymerization mechanism, any coupling is followed by the elimination of two protons, changing the $\mathrm{pH}$ at the electrode/solutions interface. At long polymerization times long oligomeric chains and low $\mathrm{pH}$ values were observed.

This mechanism also allows us to explain why under stirring at high rotation rates the electropolymerization rate decreases: in this case intermediate dimers formed around the electrode (stages III, IV, and V) were removed from the electrode neighbourhood and put into the solution.

\section{Physical Properties}

Resistance. In situ resistance measurements of the electrogenerated material were performed following the procedure of Ghalamians. ${ }^{21}$ The polymerization is carried out on two parallel platinum wires. One of the wires was then used for potenciostatic control of the polymer and the voltage drop was measured using the second wire. After the electropolymerization the polymer was transferred to the solution which contained $0.5 \mathrm{M}$

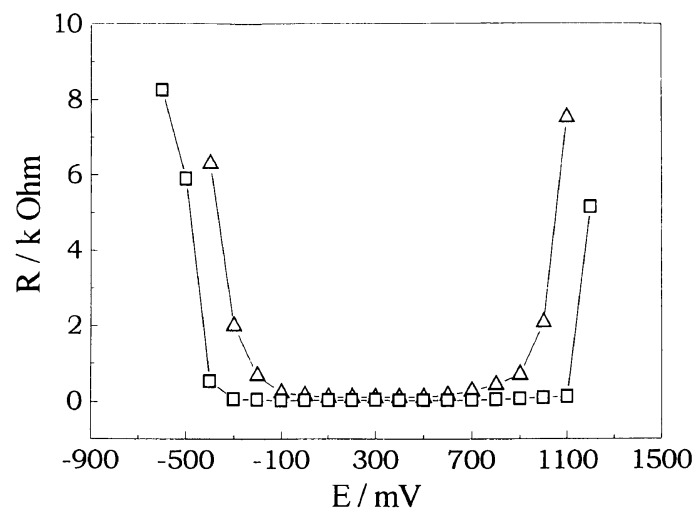

Figure 6. a) Resistance of the Ppy/CMC composite with the electrochemical potential for films growth to constant potential ( $\square$ ) and by cyclic voltammetry $(\Delta)$.

$\mathrm{H}_{2} \mathrm{SO}_{4}$, a constant potential was applied and a current flowed across the polymer/electrolyte interface. We obtained the resistance of the polymer from the relationship between the current in a steady state and the voltage drop. This voltage drop, V, was measured between both electrodes.

Two different films were electrodeposited using cyclic voltammetry, or a constant potential. The dependence of the resistance, in both cases, as a function of electrochemical potential is shown in Figure 6a. Both films showed increasing resistance at either, low potentials (lower than -0.1 , or $-0.3 \mathrm{~V}$, in films grown by cyclic voltammetry or constant potential, respectively) and high potentials (higher than 0.8 or $1.0 \mathrm{~V}$ in the same cases).

Both films became conductors inside these potential ranges. The Ppy/CMC materials have the ability to drive redox reactions, where the redox potential fits any of those values. Redox couples, whose equilibrium potentials are outside this range, are inhibited.

The films growth by a constant potential shows a conducting range of about $500 \mathrm{mV}$ larger than the conducting range of the film growth by cyclic voltammetry.

These films have been studied previously for us. ${ }^{22}$ The storage efficiencies are depending of the polymerization time and the temperature of polymerization. The means value is around of $80 \mathrm{mC} \mathrm{mg}^{-1}$ and the conductivity is in the range of $100-200 \mathrm{~S} \mathrm{~cm}^{-2}$.

The morphology of the attained films were a function of the used electrolyte, counterion, solvent or electrochemical method used during the electrodeposition. Giovani de T. Andrade et al. ${ }^{23}$ showed the influence of the first sweep on the morphology of the final film of electrogenerated polyaniline. Globular and cauliflower structures were obtained at high sweep rates. Fibrillate deposits were attained at low sweep rates. The morphology of the polypyrrole films changed from flat and uniform when was obtained by square potential waves, or cyclic voltammetry, to cauliflower structures when was obtained at a constant potential. ${ }^{24}$ In our system a globular morphology (Figure 7) was obtained when the material was generated at constant potential due to a diffusional control of the polymeric growth. At a increasing potentials of polymerization, and increasing polymerization rates, larger and more porous cauliflower structures 
(a)

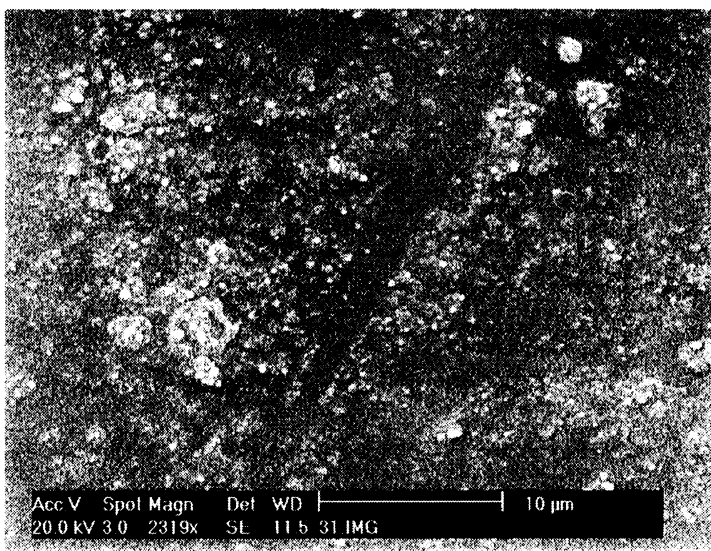

(b)

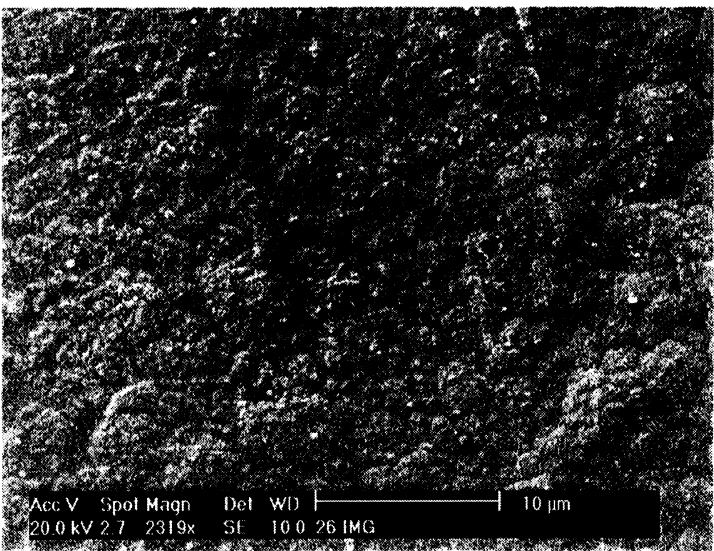

(c)

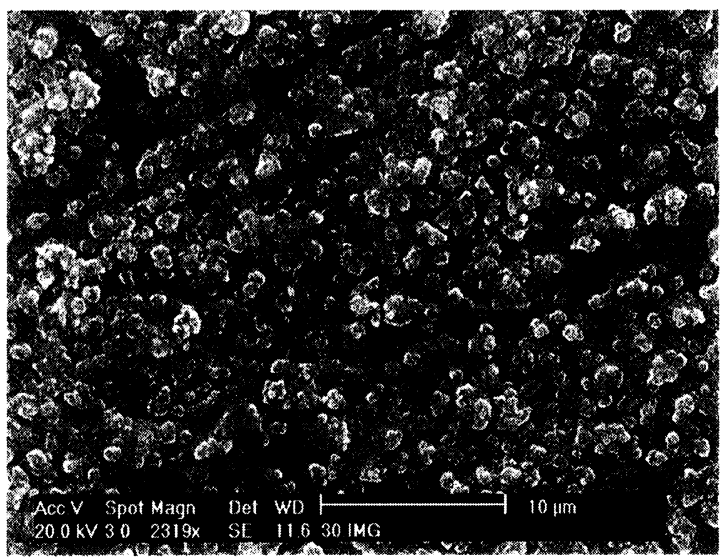

Figure 7. Micrographs of the $\mathrm{Ppy} / \mathrm{CMC}$ on $\mathrm{Pt}$ obtained in solution containing $[\mathrm{CMC}]=[\mathrm{Py}]=0.1 \mathrm{M}$ at constant potential a) $1.0, \mathrm{~b}$ ) 1.1 , and c) 1.3 during $500 \mathrm{~s}$.

were obtained. Using cyclic voltammetry during synthesis, a fibrilar and fractal structure was formed on a flat film Figures $8 \mathrm{a}$ and $8 \mathrm{~b}$.

\section{Electrodeposition on Indium Tin Oxide Substrates}

Consecutive cycles of potential were performed between -1000 and $1600 \mathrm{mV}$, at $20 \mathrm{mV} \mathrm{s}^{-1}$, using ITO as a working electrode, in $0.1 \mathrm{M} \mathrm{NaCMC}$ plus $0.1 \mathrm{M} P y$ aqueous solution which is shown in Figure 9a.

Some differences were observed relating to the voltammogram obtained on platinum (Figure 1). The monomer oxidation started at $600 \mathrm{mV}$ giving a maximum at $900 \mathrm{mV}$ and a shoulder at $1.100 \mathrm{mV}$. Along the cathodic sweep an important anodic maximum at $850 \mathrm{mV}$ was observed giving almost two times the current density that (a)

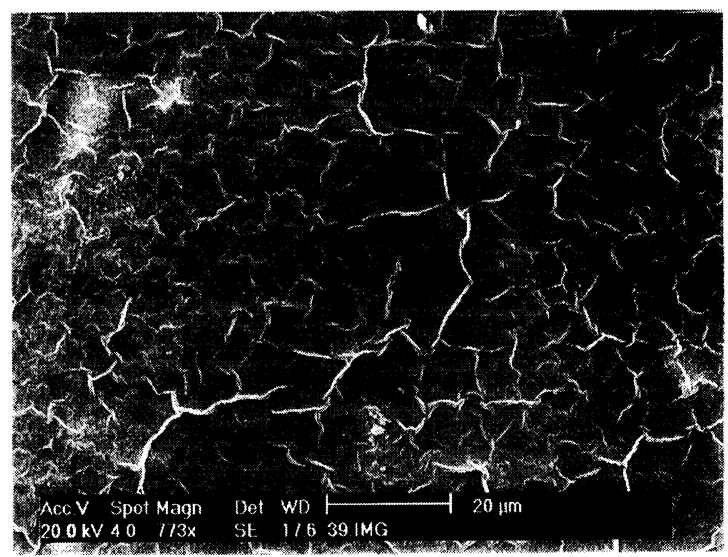

(b)

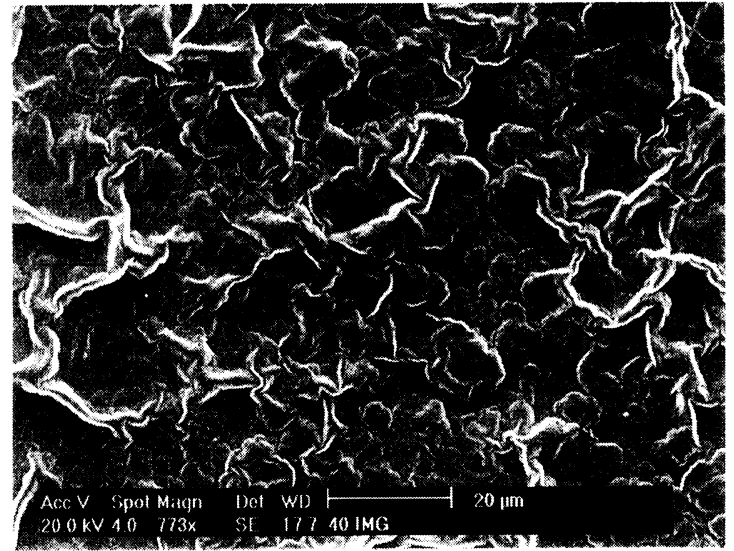

Figure 8. Micrograph of Ppy/CMC obtained on Pt by cyclic voltammetry $[\mathrm{CMC}]=0.1$ and $[\mathrm{Py}]=\mathrm{a}) 0.05 \mathrm{M}$ and b) $0.1 \mathrm{M}(50$ cycles $)$.

was observed on the anodic sweep. The electroactive polymer started to be reduced at $400 \mathrm{mV}$ giving a reduction maximum at $-850 \mathrm{mV}$. On the second and consecutive voltammograms the monomer oxidation started around $300 \mathrm{mV}$ and anodic maxima shift toward more anodic potentials on the consecutive voltammograms. These shifts point to the presence of a more resistive film coating on the electrode along the consecutive voltammograms. Nevertheless the reduction of the electroactive fraction became easier (it occurs at $-300 \mathrm{mV}$ ) than that on the film formed after the first sweep. These facts point to the electrogeneration of a compact film along the initial sweep, which can only be reduced at high cathodic overpotentials $(-850 \mathrm{mV})$. Once reduced the film was oxidised along the second sweep. The monomer oxidises at lower overpotentials on the oxidized film than it does on platinum, to give a polymer with an open structure, which can be reduced at low overpotentials.

From lower monomeric concentrations, keeping constant all the other variables, the compact film (only reducible at high cathodic overpotential) persisted along several sweeps before the growth of the more reversible films. At higher concentrations of pyrrole (0.2 M) (Figure $9 \mathrm{~b})$ the second anodic maximum on the first voltammogram showed much higher current densities than those shown by the first maxima. The electrogenerated polymer demonstrated a higher electroactivity from the first cathodic sweep giving a maximum at $-400 \mathrm{mV}$.

These facts, the presence of two anodic maxima on the first voltammogram when a clean ITO electrode was 

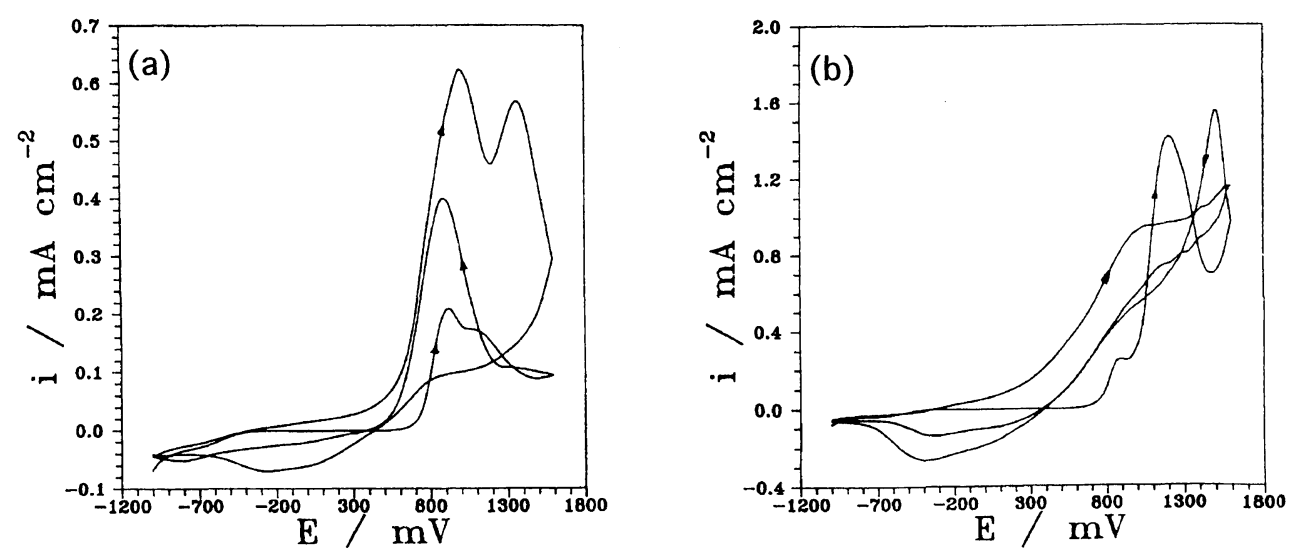

Figure 9. a) Voltammograms obtained on ITO electrode in solutions containing $[\mathrm{NaCMC}]=[\mathrm{Py}]=0.1 \mathrm{M}$ sweep rate $20 \mathrm{mV} \mathrm{s}$. b) The same conditions that in a) only $[\mathrm{Py}]=0.2 \mathrm{M}$.

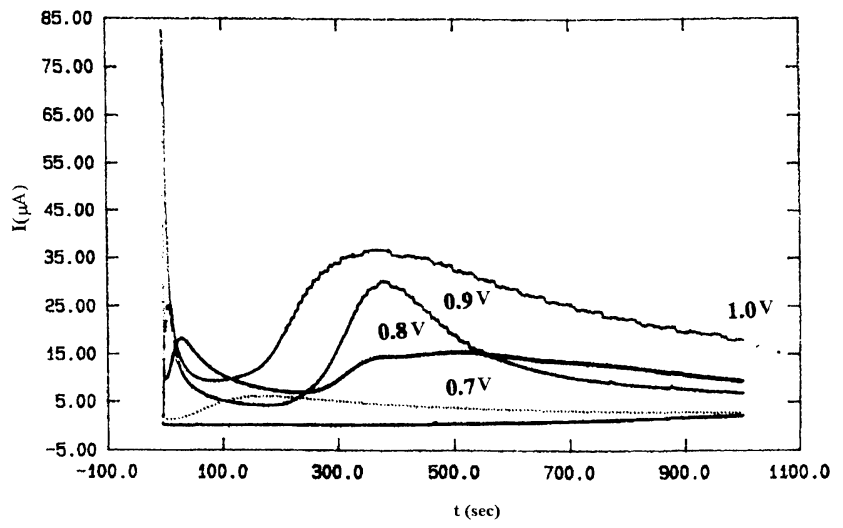

Figure 10. Chronoamperogram obtained on ITO electrode in solutions containing $[\mathrm{NaCMC}]=[\mathrm{Py}]=0.1 \mathrm{M}$ potential steps from 0 to $0.7,0.8,0.9$, and $1.0 \mathrm{~V} v$ s. SCE.

used, and the variation of the ratio between their current densities when the change in the monomer concentration, points to the presence of two different polymerization processes. An approach to these processes was explored in potential steps using a $0.1 \mathrm{M}$ pyrrole concentration. Figure 10 shows chronoamperograms performed in potential steps from $0 \mathrm{mV}$ with different anodic potentials ranging between 0.5 to $1.5 \mathrm{~V}$. A clean ITO electrode was used every time. The chronoamperogram obtained at $0.5 \mathrm{~V}$ showed a flat structure. At $0.6 \mathrm{~V}$ a maximum of current density was observed after $600 \mathrm{~s}$ of polarization. At $0.7 \mathrm{~V}$ the maximum presented higher current densities and was formed at shorter times ( $150 \mathrm{~s})$. An equivalent maximum which showed increasing current densities and formed at lower polarization times could be observed when increasing potentials of polarization, until $1 \mathrm{~V}$, were studied.

The most remarkable fact was the formation of a second maximum current at polarization times longer than $150 \mathrm{~s}$ at potentials of $0.8,0.9$, and $1 \mathrm{~V}$. At more anodic potentials only a nucleation process was observed becoming like a diffusion control process at $1.3 \mathrm{~V}$.

From all of these results it is clear that different processes, take place when changing different potentials. This can be corroborated by the different morphology obtained on the films. A voltammetric study at different sweep rates indicated that the first peak of the voltam- mogram was controlled by surface reaction, when the second film was under diffusion control. Results are similar to those obtained using a platinum electrode.

Comparing these results using platinum or ITO electrodes, we observed more important nucleation loops on the voltammograms using ITO electrodes. M. Zhou et $a l .{ }^{25}$ concluded that these systems have a similar behavior to the metal deposition on different substrates. Under these conditions a similar mechanism of nucleation and growth seemed to occur on both electrodes.

\section{Physical Properties}

Morphology. Probably the most interesting results of this work are those related to the morphology of the Ppy/ $\mathrm{CMC}$ on indium tin oxide electrodeposited in some conditions.

Films formed on ITO at $0.8,1.1$, and, $1.3 \mathrm{~V}$ were observed by SEM and they are shown in Figures 11a, 11b, and $11 \mathrm{c}$ respectively. A roughness structure showing a great population of nucleus per unit of area was formed at $0.8 \mathrm{~V}$. When the potential increased to $1.1 \mathrm{~V}$ on a flat film, an irregular fold was formed. At $1.3 \mathrm{~V}$, under overall diffusion control, dendrites were formed with some remaining folds. These morphologies were very repetitive. At $1.3 \mathrm{~V}$ the electrode always finished coated with dendritic formation. The shape of these dendrites represents changes from one electrode to another, but usually every electrode showed different morphologies for those dendrites from different parts. Micrographs in Figures $12 \mathrm{a}, 12 \mathrm{~b}$, and $12 \mathrm{c}$ show the most usual morphologies.

When the monomer concentration was decreased to $0.05 \mathrm{M}$ the polymeric film obtained at $1.3 \mathrm{~V}$ showed a morphology similar to that observed on the micrograph 11a. This was similar to the one obtained at lower potentials from $0.1 \mathrm{M}$. The use of a higher monomeric concentration gave globular structures on a flat film.

The formation and growth of dendrites normally on the surface has been previously described as diffusion controlled aggregation (DCA) in absence of crystalline anisotropy. ${ }^{26,27}$ In our system CMC was adsorbed on the electrode and a polymerization of pyrrole seemed to occur through this layer. At the same time new CMC is adsorbed giving a compact and low conducting film which can be deduced from chronoamperograms performed at lower potentials than $0.8 \mathrm{~V}$. At more anodic potentials 
(a)

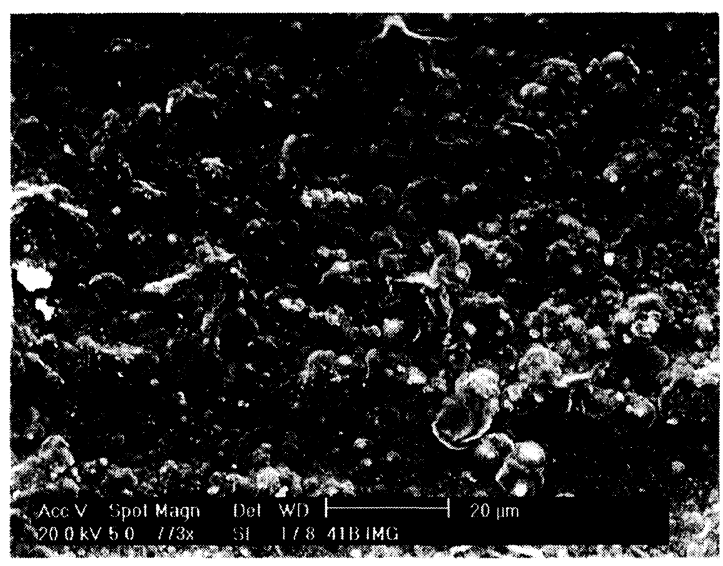

(b)

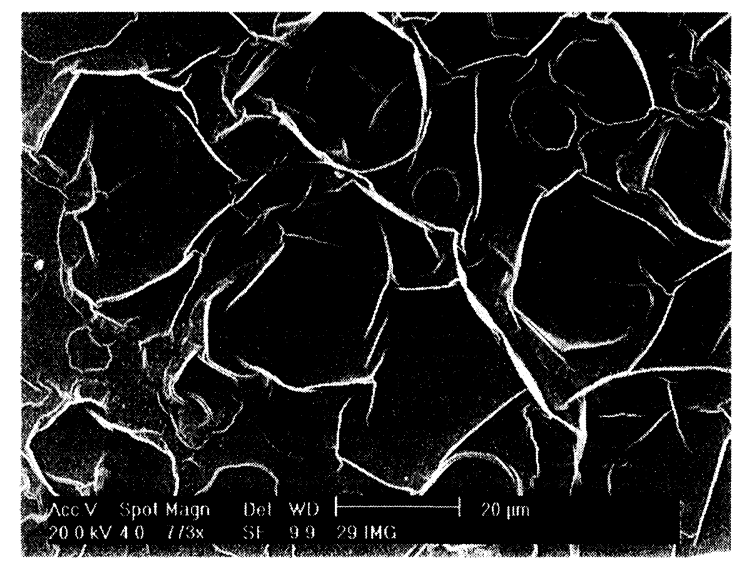

(c)

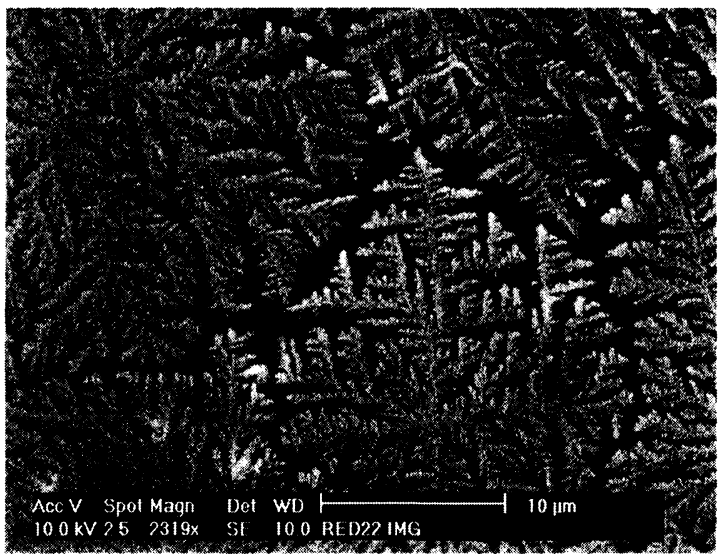

Figure 11. Micrograph of Ppy/CMC obtained on ITO at constant potential a) 0.8 , b) 1.0 , and c) $1.3 \mathrm{~V}$. The composites have been obtained in solution containing $[\mathrm{NaCMC}]=[\mathrm{Py}]=0.1 \mathrm{M}$.

these films grew faster and instabilities appeared along the lines, showing a fast growth of the polymer along these lines, and a slow growth from the lines inside the surface. When higher potentials were used instabilities focused on the points of the fast formed film under diffusion limited polymerization (the concentration of pyrrole fell to zero on the surface very fast). Under these conditions only these points were conducting enough to allow the formation of dendrites growing perpendicular to the conducting point, that means, parallel to the non conducting film and parallel to the electrode surface. This observation is consistent with Kaufman et al. ${ }^{28}$ They observed that increasing oxidation potential in a quasi two dimensional cell, the fractal dimension of the advancing growth front drops from approximately two to one as (a)

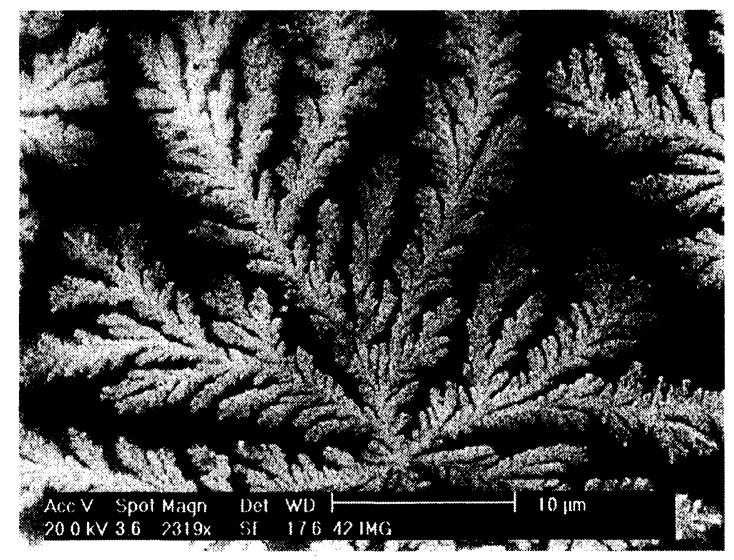

(b)

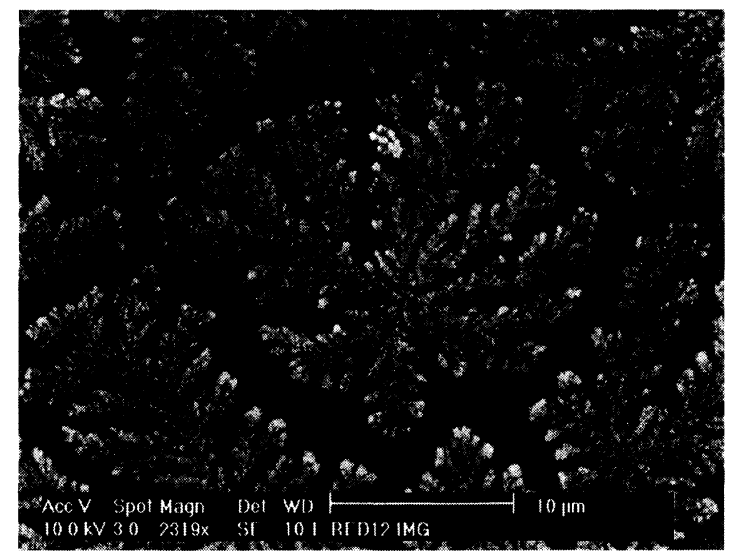

(c)

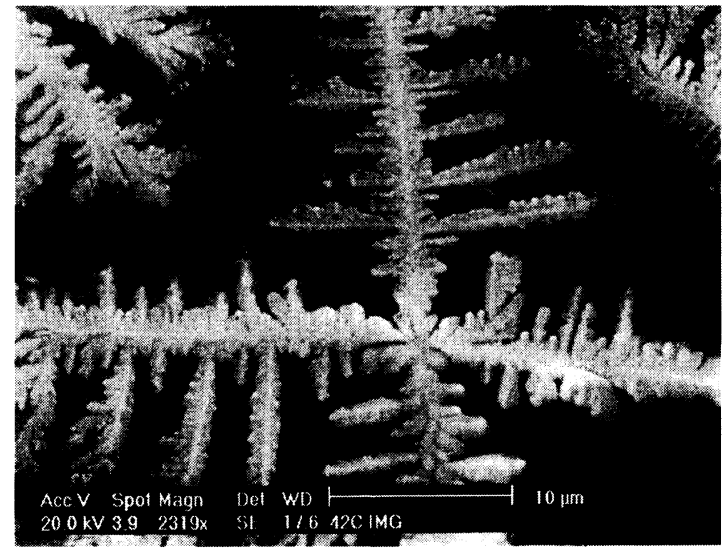

Figure 12. a) Dendritical morphology of a sample obtained at 1.3 $\mathrm{V} v s$. SCE during $30 \mathrm{~s}$ on ITO substrate obtained in solution containing $[\mathrm{NaCMC}]=[\mathrm{Py}]=0.1 \mathrm{M} . \mathrm{b})$ and $\mathrm{c}$ ) the same condition that in Figure 12a but different dendritical morphologies. In same cases these kind of morphologies can be obtained in the same sample obtained in these conditions.

growth becomes dendritic.

\section{CONCLUSIONS}

A Ppy/CMC has been synthesised by electrochemical process on platinum and tin oxide substrates. The polymerization mechanism seems to be the same; with the first process controlled by a surface reaction and the second one controlled by diffusion. The morphology of the surface is quite different in the same electrodeposition conditions for both substrates. In the case of tin oxide when the concentration of Py and CMC are $0.1 \mathrm{M}$ and 
the potential applied is $1.3 \mathrm{~V} v$ s. SCE, the morphology of the deposit has different sizes and forms. This special growing of the first layer produced irregularities where the energy was less and the polymerization was preferential in its irregularities.

The electrical characteristic of these composites is very similar to the polypyrrole with respect to the stability. The edges of potential where the composite are able to drive a redox reaction without degradation of itself are -400 and $1100 \mathrm{mV}$.

\section{REFERENCES}

1. J. Wang, S. P. Chem, and M. S. Lin, J. Electroanal. Chem., 273, 231 (1989).

2. S. Dang, Z. Sund, and Z. Lu, Analyst, 113, 1525 (1983).

3. H. Mao and P. G. Pickup, J. Electroanal. Chem., 265, 127 (1989).

4. H. S. White, G. P. Kittlesen, and M. S. Wrighton, J. Am. Chem. Soc., 106, 7389 (1984).

5. H. Yoneyama, K. Wakamoto, and H. Tamura, J. Electrochem. Soc., 132, 2414 (1985).

6. P. J. Nigrey, D. Macinnes, J.r., G. MacDiarmid, and A. J. Heegon. J. Electrochem. Soc., 128, 1651 (1981).

7. H. Shirakawa, S. Okada, M. Aizawa, J. Yoshitake, and S. Suzuki, Synth. Met., 4, 43 (1981).

8. B. Zinger and L. L. Miller, J. Am. Chem. Soc., 106, 6861 (1984).

9. L. L. Miller and Q. X. Zhon, Macromolecules, 20, 1594 (1987)

10. S. Asavapiriyanont, G. K. Chandler, G. A. Gunawardena, and D. Pletcher, J. Electroanal, Chem., 177, 229 (1984)

11. P. G. Pickup and R. A. Osteryoung, J. Am. Chem. Soc., 106,
2294 (1984).

12. R. E. Noftleand and D. Pletcher, J. Electroanal. Chem., 229, 227 (1987)

13. B. R. Scharifker, E. Garcia-Pastoriza, and W. Marino, J. Electroanal. Chem., 300, 85 (1991).

14. R. John and G. Wallace, J. Electroanal. Chem., 306, 157 (1991).

15. D. Rosseins Ky, N. Norse, R. Slade, G. Hix, R. Mortimer, and D. Walton, Electrochim. Acta, 36, 733 (1991).

16. I. Rodríguez, M. Marcos, and J. González Velasco, Electrochim. Acta, 32, 1181 (1987).

17. A. Díaz, J. Grownley, J. Bargon, G. P. Gardini, and J. Torance, J. Electroanal. Chem., 121, 355 (1981).

18. J. L. Bredas, R. Silbey, D. S. Boudreaux, and R. R. Chance, J. Am. Chem. Soc., 105, 6555 (1983)

19. D. J. Fermín and B. R. Scharifker, J. Electroanal. Chem., 357, 273 (1993).

20. B. R. Scharifker and D. J. Fermín, J. Electroanal. Chem., 365, 35 (1994).

21. M. Ghalamians, T. N. Suresk Duman, A. Q. Contractor, Proc. - Indian Acad. Sci., Chem. Sci., 97, 457 (1986).

22. T. F. Otero, P. Herrasti, P. Ocón, and C. R. Alves, Electrochim. Acta, 43, 1089 (1998).

23. G. de T. Andrade, M. J. Aguirre, and S. R. Biaggio, Electrochim. Acta, 44, 633 (1998).

24. T. F. Otero and E. De Larreta-Azelain, J. Chem. Phys., 86, 131 (1987).

25. M. Zhou and J. Heinze, Electrochim. Acta., 44, 1733 (1999),

26. M. M. Mullins and R. F. Sekerka, J. Appl. Phys., 34, 323 (1963).

27. J. S. Langer, Rev. Mod. Phys., 52, 1 (1980).

28. J. H. Kaufman, O. R. Melroy, F. F. Abraham, A. I. Nazzal, and A. Kapitulnik, Synthetic Metals, 18, 19 (1987). 